\title{
Sexual dysfunction and associated factors among patients with epilepsy at Amanuel Mental Specialty Hospital, Addis Ababa - Ethiopia
}

Alem K. Ejigu ${ }^{1 *}$ (D, Kelemwa H. Zewlde ${ }^{1}$, Niguse Y. Muluneh², Zehara R. Seraj ${ }^{1}$, Mahlet W. GebreLibanos ${ }^{1}$ and Yodit H. Bezabih ${ }^{1}$

\begin{abstract}
Background: Many patients with chronic illness have sexual dysfunction that may be related to the condition itself, drug side effects, emotional sequel, or a combination of those factors. Patients with epilepsy are no exception. Men and women with epilepsy are frequently complaining sexual dysfunction and they appear to have a higher incidence of sexual dysfunction than peoples with other chronic neurologic illness. These problems can have a substantial impact on their sexuality thus; it needs careful study and evaluation.

Methods: Hospital based cross sectional study was conducted from January to July, 2016 among Patient with Epilepsy at Amanuel Mental Specialty Hospital. Interviewer administered Changes in Sexual Functioning Questionnaire (CSFQ-14) was used in order to assess the sexual problems. Finally, the data was analyzed by using Statistical Package for Social Science (SPSS) V-20. Descriptive statistics and logistic regression were used to describe the variables. Levels of significance of association determined at $<0.05$.

Results: A total of 694 respondents participated, with response rate $99.14 \%$. Among them 576 completed all items. The result showed that 363 subjects $(63.9,95 \% \mathrm{Cl}=59.5-67.7)$ had global sexual dysfunction. Furthermore, the rate of sexual dysfunction was reported as $55.6 \%(95 \% \mathrm{Cl}=49.1-62.6)$ and $67.4 \%(95 \% \mathrm{Cl}=62.8-72.1)$ in female and male participants, respectively. Among domains of sexual dysfunction; sexual arousal problem $(97.8 \%(95 \% \mathrm{Cl}=95.8-98.3))$ and sexual pain problem $(11.3 \%(95 \% \mathrm{Cl}=8.8-13.9))$ were the most and the least prevalent sexual dysfunctions respectively. Concerning associated factors; age grouped $>51$, depression, being out of relationship or not satisfied with non-sexual aspect of relationship, being jobless and khat use has positive association with sexual dysfunction. By the other side alcohol use, level of education \& age groups 18-21 years associated negatively.
\end{abstract}

Conclusions: The prevalence of sexual dysfunction among patients with epilepsy is very high; its prevalence is more among males than females. Sexual arousal problem and sexual pain problem were the most and the least prevalent sexual dysfunctions respectively.

Keywords: Sexual dysfunction, Epilepsy, Ethiopia, Amanuel hospital

\footnotetext{
* Correspondence: alemkebede_2005@yahoo.com

${ }^{1}$ Addis Ababa, Ethiopia

Full list of author information is available at the end of the article
}

(c) The Author(s). 2019 Open Access This article is distributed under the terms of the Creative Commons Attribution 4.0 International License (http://creativecommons.org/licenses/by/4.0/), which permits unrestricted use, distribution, and reproduction in any medium, provided you give appropriate credit to the original author(s) and the source, provide a link to the Creative Commons license, and indicate if changes were made. The Creative Commons Public Domain Dedication waiver (http://creativecommons.org/publicdomain/zero/1.0/) applies to the data made available in this article, unless otherwise stated. 


\section{Background}

The quality of human life is a summation of many factors. Male and female sexuality, relationships and successful reproduction are paramount in the accomplishment of a meaningful life for most individuals [1-3]. Sexual function is the physiological capacity to experience desire, arousal, and orgasm. Sexual dysfunctions are a heterogeneous group of disorders that are typically characterized by clinically significant disturbances in a people's ability to respond sexually or to experience sexual pleasure $[4,5]$.

Sexual dysfunction as a disorder is complex and often multi factorial, with medical, psychological, and life circumstances all playing important roles [6-9]. Epilepsy (a chronic neurologic disorder the hallmark of which is recurrent, unprovoked seizures) is one of neurological disorder which can cause sexual dysfunction. Sexual disorders (both hypo-sexuality and sexual dysfunction) are common in patient with epilepsy, occurring in up to two thirds of patient with epilepsy (PWE) [10]. Men and women with epilepsy frequently complain, if asked, of sexual dysfunction and appear to have a higher incidence of sexual dysfunction than peoples with other chronic neurologic illness.

The aim of this cross-sectional study was to assess the magnitude of sexual dysfunction and factors associated with it among PWE at Amanuel Mental Specialty Hospital, Addis Ababa, Ethiopia. The findings of this study could be useful evidence for designing proper intervention and possible managements for professionals and responsible organs.

\section{Methods}

\section{Study design and study period}

Institutional based cross sectional study was conducted from May 15 to June 30, 2016.

\section{Study area}

An institution based study was conducted at AMSH, AA - Ethiopia. The hospital has different teams. Neuro Epileptic Case Team (NEP) is one of health service team in the hospital. There are about 34,210 PWE who have regular follow up in a year at hospital's NEP clinics. Among them 11,634 (34\%) are females [11]. Averages of 1900 cases are seen monthly (AMSH, Central statistic bureau). The area is selected because of high patient flow which has good opportunities to trace patients who can be representative for the study population.

\section{Population}

\section{Source population}

Our source populations were all PWE who present for follow up visit at AMSH, NEP clinics.

\section{Study population}

Our study populations were PWE in the age group 18 and above who were presented for follow-up visit at AMSH NEP clinics in the study period.

\section{Eligibility criteria}

PWE age 18 and above, who had sexual experience for six or above months were included in this study.

PWE who is on ectal or post-ectal phase were not included in this study.

\section{Sample size \& sampling procedure Sample size}

The minimum number of sample required for this study determined by using power population proportion formula considering the following assumptions;

95\% confidence level, 50\% sexual dysfunction and 5\% margin of error

$$
\begin{aligned}
& n=\frac{\left(\frac{Z \alpha}{2}\right)^{2} p(1-P)}{d^{2}} \\
& n=\frac{(1.96)^{2} 0.5(1-0.5)}{(0.05)^{2}}=384
\end{aligned}
$$

In Ethiopian culture, openly discussing on issues related with sexuality is taboo and not common. By considering such conditions and other studies non respondent rate this study was used a maximum non respondent rate; $15 \%$. Thus; the total sample size calculated with single population proportion to study prevalence of sexual dysfunction among PWE.

$$
384+(384 * 15 \%(384))=442 .
$$

To address associated factors, final sample size was calculated by using power population proportion as:

$$
\begin{aligned}
608+(608 * 15 \%(608)) & =608+91.2 \\
& =699.2 \approx 700
\end{aligned}
$$

\section{Sampling procedure}

Our study participants were select from AMSH, NEP OPDs through stratified systematic random sampling technique. Sample size was allocated proportionally for each sex categories (66\% for male and $34 \%$ for female participants). Sampling interval was determined by dividing total study population; 2850 PWEs [11]; who had follow up during six weeks data collection period by total sample size (700). The sampling fraction was: 2850/ $700=4.07$. Approximately five was taken not to miss respondents in the sampling fraction above four (0.07). The first respondent was selected by lottery method from the first five study population for each strata, and 
the next respondent was chosen at regular intervals of every 5 th cases in each sex categories.

\section{Instruments used for data collection and data collection procedures \\ Instruments used for data collection}

In this study, to assess Socio-demographic information, clinical data, quality of sexual functioning and factors associated with sexual dysfunction; We mainly used Couples Satisfaction Index (CSI) scales to assess participant's satisfaction on their relationship, Daily Stress Full Life Events Measurement Scale (DSLEMS) to assess presence of Stressful Life Events and to obtain socio-demographic and clinical data a detailed self-designed semi structured questionnaire was administered to study participant.

Sexual response was measured by using Changes in Sexual Functioning Questionnaires (CSFQ-14-) which have separate forms for female (CSFQ - Female Clinical Version) and male (CSFQ - Male Clinical Version) data. CSFQ has 14 items on a single sheet and it is used to assess the existence of sexual problems in study participants. All the 14 items should be answered on a five point (Likert type) scale to assess global sexual dysfunction. Eleven of the items from "Never", through "Rarely", "Sometimes", and "Often", to "Every day"; the rest three of the items which has reverse scored from No", through "Little", "Some", and "much", to "Great". In addition other CSFQ domains; Sexual Desire, Pleasure, arousal/ excitement and Orgasm/Completion can be obtain and represent as a profile. The CSFQ-14- has chosen because it is standard, have a brief, valid, reliable, relatively unobstructive, available and gender-specific questionnaire to monitor sexual functioning. Also it has Cronbach's $\alpha$ 0.91 and 0.93 for the male and female scales, respectively [12].

The English version of instruments was translated to Amharic language and retranslate to English by accepted psychiatric professionals. For participants in different languages, translators were assisting data collectors.

\section{Data collection procedures}

Data collectors got brief orientation on the data collection procedure and data collection protocol before they engage into actual data collection activities. Three health officers and three BSC nurses (four males and two females) were recruited to collect data. Amharic Version of structured and semi structured interviewer administered questionnaire was used. It has six parts: The 1st part contains socio-demographic characteristics of participants; the 2nd part contains "Changes in Sexual Functioning Questionnaires (CSFQ)"; the ${ }^{3 \text { rd }}$ and the 4th parts were containing Relationship Assessment Scale (RAS) and Self-esteem scale respectively, Daily Stressful Life Events Measurement Scale (DSLEMS) was the 5th tool used to assess Stressful Life Event/s and the last part contains clinical data of participants. This tools were administered to 700 eligible clients at AMSH; NEP clinics during the study period. Privacy of participants was given special consideration before the beginning of data collection. To make the communication easy female data collectors were expected to contact female subjects and the same procedure were performing for male subjects. Two separate OPDs (NEP OPD-3rd for males and $\mathrm{MCH}$ OPD for females) were used to obtain data from each sex categories.

\section{Definition of variables}

Sexual Dysfunction was dependent variable and independent variables were Psychosocial factors (quality of relationship, stressful life event/s, self-esteem), Demographic factors (age, sex, education, occupation, relationship status), Clinical factors (comorbid conditions, medication for comorbidities, obesity), Illness related factors (type of AEDs, seizure experience (uncontrolled/ controlled), age onset of epilepsy, medication regimen, type of epilepsy], Behavioral factor (alcohol use, khat use or/and cigarette use).

Sexual dysfunction: it is explained by total scores below the cutoff points from all 14 CSFQ elements; below 41 and 47 for female and male participants respectively [12].

Sexual dissatisfaction: it is explained by scoring less than 5 from CSFQ-14- (item one).

Sexual desire problem: it is explained by scoring less than 16 for females and less than 20 for males from the sum of CSFQ-14- (items 2 through 6).

Arousal/excitement dysfunction: it is explained by scoring less than 13 for females and less than 14 for males from the sum of CSFQ-14- (items 7 through 9).

Anorgasmia: it is explained by scoring less than 12 for females and less than 14 for males from the sum of CSFQ-14- (items 11 through 13).

Dyspareunia: it is explained by scoring less than 5 for both sex categories from the CSFQ - 14- (item teen).

Quality of relationship: it is explained by score above 15 from the summation of Relationship Assessment Scale called the more satisfied with his/her relationship $[8,13]$.

Poor self-esteem: is defined as score below 15 on Rosenberg self-esteem scale.

Khat: is a flowering plant native to the Horn of Africa and the Arabian Peninsula. It contains the alkaloid cathinone, a stimulant, which is said to cause excitement, loss of appetite and euphoria [14].

Comorbid illness: is defined as presence of additional illness among PWE; which includes previously confirmed psychosis, depression, hypertension, diabetic mellitus, and asthma. 
Stressful Life Event: experiencing one or more from listed ten items within the past six months from time of data collection.

Poly therapy: taking two or more than two types of AEDs.

Underweight: BMI less than $18.5 \mathrm{Kg} / \mathrm{m}^{2}$.

Normal weight: BMI in the range 18.5 to $24.99 \mathrm{Kg} /$ $\mathrm{m}^{2}$.

Overweight: $\mathrm{BMI}$ in the rages of 25 to $29.99 \mathrm{Kg} / \mathrm{m}^{2}$.

\section{Data processing and analysis}

Data was code and entered to Epi-Info version 7 for cleaning, storing and recording. It was imported to computer software Statistical Package for Social Sciences (SPSS) version 20. Descriptive statistical procedures was utilize to estimate the prevalence of sexual dysfunction and to describe other variables. Bivariate and multivariable logistic regression analyses were conducted to identify associated factors of sexual dysfunction among PWE. The strength of the associated factors was presented by odds ratio with $95 \% \mathrm{CI}$. The independent variables that fulfill $p$-value less than 0.2 were tolerated and exported to multivariable logistic regression. $P$-value less than 0.05 were considered as statistically significance.

The data was mainly analyzed as global sexual dysfunction and factors associated with sexual dysfunction. It also reported separately based on sex categories and in each domains of sexual dysfunction in each sex categories.

\section{Results}

Description of socio-demographic characteristics of the respondents by sex

This study enrolled 694 participants with response rate 99.14\%. Among them 460 were males; mean age $31 \pm$ 11.17 yrs. (range 18 to75); mean age of females was $32.46 \pm 11.17$ years (range 18 to 72 year). Most participants $(70.0 \%)$ were in relationship and $56.6 \%$ of respondents have children. Around $38 \%$ of participants were employee; more females (33.8\%) were employed than males $(29.3 \%)$. About $38.2 \%$ of respondents had secondary level of education. Thirty six (6.5\%) respondents had college degree \& above, only six; $2.6 \%$; of them were females (Socio-demographic characteristics of the respondents by sex (Table 1)).

\section{Description of psychological factors among patient with epilepsy by sex}

From all participants 50 (7.2\%) have substance use behavior. Among them eight were female. Khat is more frequently $(9.6 \%)$ used substance than cigarette $(2.1 \%)$ and alcohol (3.3\%). Almost all (98.6\%) participants have good self esteem. Majority (83.1\%) of respondents were experienced stressful life events in the past six months.
Female participants were slightly stressful than males (88.5\% compared to $80 \%)$. Most (41.2\%) of participants are satisfied with non-sexual aspects of their relationship (Psychosocial characteristics of participants -Table 2).

\section{Description of clinical factors among patient with epilepsy by sex}

Epilepsy began between 6 months and 57 years of age (mean 18.28 \pm 11.57 ). Among all participants $38.9 \%$ experienced seizure attacks in the past one month of the study period. Female participants were experiencing seizure attacks more than males $(43.2 \%$ compare to $36.7 \%)$. Twenty six percent of participants have controlled seizure. Among them $70 \%$ are males. In medication regimen; 76.1\% PWEs were under monotherapy. Phenobarbitone was the most commonly prescribed and combined AED. Twenty four percent of participants have co-morbid illness. Hypertension was more frequent (6.2\%) medical illness followed by diabetics (4.9\%) and HIV/AIDS (5.9\%). Depression was more frequent mental illness (4.9\%) than psychosis (3.3\%), and it has equal distribution among female and male participants (7.3\%). Majority of participants (74.2\%) were in normal ranges of BMI, female participants were more underweight than males $(13.7 \%$ compare to $8.9 \%)$ (Clinical factors of participants - Table 3).

\section{Prevalence of sexual dysfunction among patient with epilepsy}

Among all (694) respondents, 583 (84\%) had sexual experience for six months and above from data collection date. Among those 583, 576 (98.79\%) were completed the CSFQ-14 all items \& they were included in the analysis part of global sexual dysfunction, sexual pain problem (dyspareunia), sexual pleasure and orgasmic dysfunction. And other domains of sexual dysfunction; sexual desire and sexual arousal problem; were analyzed based on 694 (99.14\%) respondents. More males (70.26\%) than females (29.74\%) provided data for Changes in Sexual Functioning Questionnaire (CSFQ-14).

\section{Prevalence of global sexual dysfunction among PWE}

Prevalence of global sexual dysfunction among patient with epilepsy is $63.9 \%(95 \% \mathrm{CI}=59.5-67.7)$. It is more prevalent among males than that of females $(67.4 \%$ $(95 \% \mathrm{CI}=62.8-72.1) \quad$ to $55.6 \% \quad(95 \% \mathrm{CI}=49.1-62.6))$ (Fig. 1).

\section{Prevalence of sexual dysfunction in each domains of sexual dysfunction}

In each domain; prevalence of sexual arousal problem among PWE is higher; 97.8, 95\%CI; 95.8-98.3; and sexual pain problem is lower; $11.3,95 \% \mathrm{CI}$; 8.8-13.9; than other domains (Fig. 2). 
Table 1 Socio-demographic characteristics of patient with epilepsy by sex at Amanuel Mental Specialized Hospital: Addis Ababa, Ethiopia - 2016

\begin{tabular}{|c|c|c|c|}
\hline Variable & Over all sample $(n=694)$ & Females $(n=234)$ & Males $(n=460)$ \\
\hline Sex & 694 & $234(33.7 \%)$ & $460(66.3)$ \\
\hline \multicolumn{4}{|l|}{ Age } \\
\hline$<21$ & $69(9.9)$ & $34(14.5)$ & $35(7.6)$ \\
\hline $21-30$ & $284(40.9)$ & $91(38.9)$ & $193(42.0)$ \\
\hline $31-40$ & $195(28.1)$ & $64(27.4)$ & $131(28.5)$ \\
\hline $41-50$ & 89 (12.8) & $28(12)$ & $61(13.3)$ \\
\hline$>50$ & $57(8.2)$ & $17(7.3)$ & $40(8.7)$ \\
\hline \multicolumn{4}{|l|}{ Ethnicity: n (\%) } \\
\hline Oromo & $204(29.4)$ & $68(29.1)$ & $136(29.6)$ \\
\hline Amhara & $271(39.0)$ & 89 (38.0\%) & $182(39.6)$ \\
\hline Guragie & $140(20.2)$ & $50(21.4)$ & 90 (19.6) \\
\hline Other & 79 (11.4) & $27(11.5)$ & $52(11.3)$ \\
\hline \multicolumn{4}{|l|}{ Religion: n (\%) } \\
\hline Orthodox & $466(67.1)$ & $155(66.2)$ & $311(67.6)$ \\
\hline Muslim & $139(20.0)$ & $42(17.9)$ & $97(21.1)$ \\
\hline Protestant & $82(11.8)$ & $33(14.1)$ & $49(10.7)$ \\
\hline Other & $7(1.0)$ & $4(1.7)$ & $3(0.6)$ \\
\hline \multicolumn{4}{|l|}{ Relationship status: n (\%) } \\
\hline In relationship & $486(70.0)$ & $167(34.4)$ & $319(65.6)$ \\
\hline Not in relationship & $208(30.0)$ & $67(28.6)$ & $141(30.7)$ \\
\hline \multicolumn{4}{|l|}{ Occupation: n (\%) } \\
\hline Employee & $214(30.8)$ & 79 (33.8) & $135(29.3)$ \\
\hline Jobless & $159(22.9)$ & $71(30.3)$ & $88(19.1)$ \\
\hline Self-employee & $190(27.4)$ & $24(10.3)$ & $116(36.1)$ \\
\hline House wife & $43(6.2)$ & 43 (17.6) & - \\
\hline Student & $32(4.6)$ & $12(5.1)$ & $20(4.3)$ \\
\hline Farmer & $56(8.1)$ & $9(3.8)$ & $47(10.2)$ \\
\hline \multicolumn{4}{|l|}{ Education: n (\%) } \\
\hline No formal education & 108 (15.6) & 48 (20.6) & $60(13.0)$ \\
\hline Primary school & $218(31.5)$ & $68(29.2)$ & $150(32.6)$ \\
\hline Secondary S. & $265(38.2)$ & 90 (38.6) & $175(38.0)$ \\
\hline Diploma & $66(9.5)$ & $21(9.0)$ & $45(9.8)$ \\
\hline Degree \& above & $36(5.2)$ & $6(2.6)$ & $30(6.5)$ \\
\hline \multicolumn{4}{|l|}{ Have Children: n (\%) } \\
\hline Yes & $393(56.6)$ & $138(59.0)$ & $255(55.4)$ \\
\hline No & $301(43.4)$ & $96(41.0)$ & 205 (44.6) \\
\hline
\end{tabular}

Prevalence of domains of sexual dysfunction by sex

Sexual pain problem is the least prevalent; 6.4\% (95\% CI; 11.7-23.2) for females \& 9.1\% (95\% CI; 6.2-11.9) for males; domain of sexual dysfunction in both sex categories. Other domains are highly prevalent among both sex categories (Fig. 3).
Factors associated with sexual dysfunction among patient with epilepsy

The binary logistic (crude analysis) was done on sociodemographic variables (Age, relationship status, occupation, educational status), clinical variables (depression, psychosis, AED; Phenytoin, carbamazepine, $\mathrm{Na}$ valporate and 
Table 2 Description of psychosocial characteristics of patient with epilepsy at Amanuel Mental Specialized Hospital: Addis Ababa, Ethiopia; 2016

\begin{tabular}{|c|c|c|c|}
\hline Variables & Over all sample: $n=694$ & Females: $n=234$ & Males: $n=460$ \\
\hline \multicolumn{4}{|l|}{ Substance use: n (\%) } \\
\hline Yes & $50(7.20)$ & $8(3.40)$ & $42(9.10)$ \\
\hline No & $644(92.80)$ & $226(96.60)$ & $418(90.90)$ \\
\hline \multicolumn{4}{|c|}{ Types of substance: n (\%) } \\
\hline Khat & $38(9.60)$ & $6(2.60)$ & $32(7.00)$ \\
\hline Cigarette & $12(2.10)$ & $3(2.20)$ & $9(1.80)$ \\
\hline Alcohol & $19(3.30)$ & $2(1.20)$ & $17(4.20)$ \\
\hline \multicolumn{4}{|c|}{ Stressful life events: n (\%) } \\
\hline Yes & $577(83.10)$ & $207(88.50)$ & $370(80.40)$ \\
\hline No & $117(16.90)$ & $27(11.50)$ & $90(19.60)$ \\
\hline \multicolumn{4}{|l|}{ Self-esteem: n (\%) } \\
\hline Good & $568(98.60)$ & $167(97.7)$ & $401(99.00)$ \\
\hline Poor & $8(1.40)$ & $4(2.30)$ & $4(1.00)$ \\
\hline \multicolumn{4}{|c|}{ Relationship satisfaction: n (\%); } \\
\hline Satisfied & $286(41.20)$ & $90(38.50)$ & $196(42.60)$ \\
\hline Not satisfied & $200(28.80)$ & $77(32.90)$ & $123(26.70)$ \\
\hline Not in relationship & $208(30.00)$ & $67(28.6)$ & $141(30.70)$ \\
\hline
\end{tabular}

phenobarbitone; medication regimen, body mass, episode of seizure, age onset of epilepsy) and psychosocial variables (current alcohol use, khat use, cigarette use, stressful life event/s, relationship satisfaction and self-esteem).

Variables that found to be $p$-value of less than 0.2 in Univariate logistic regression (age, level of education, occupation, stressful life event, relationship status, khat adulis use, alcohol use, cigarette use, type of medication and medication regimen, age onset of epilepsy, seizure experience, and obesity) are taken in to multivariable logistic regression. The variable group expected to be protective against sexual dysfunction is treated as the reference group.

The odds of developing sexual dysfunction decreased by $74 \%$; $(\mathrm{AOR}=0.26,95 \% \mathrm{CI}=0.12-0.60)$; among participants in the age group under 21. But it increased 3.23 times; $(\mathrm{AOR}=3.23,95 \% \mathrm{CI} ; 1.21-8.67)$; among the age group above 51 .

The odds of developing sexual dysfunction is decreased by $65 \%$; $(\mathrm{AOR}=0.35,95 \% \mathrm{CI}=0.17-0.71)$; and $73 \%$; $(\mathrm{AOR}=0.30,95 \% \mathrm{CI}=0.12-0.72)$; among level of education at $2^{\text {ndry }}$ and diploma levels when it compared with those at $1^{\text {ry }}$ level.

The odds of developing sexual dysfunction were decreased by $74 \%$; $(\mathrm{AOR}=0.26 ; 95 \% \mathrm{CI}=0.075-0.87)$; in alcohol users compared with not alcohol users.

In the variable occupation, the odds of developing sexual dysfunction is increased 2.59; $(\mathrm{AOR}=2.59,95 \% \mathrm{CI}=$ 1.34-5.03); times among jobless when it compared with the employed one.
The odds of developing sexual dysfunction is 6.28; $(\mathrm{AOR}=6.28, \quad 95 \% \mathrm{CI}=1.67-23.61) ; \quad$ times increased among depressed patients when it compared with people without depression.

The risk of developing sexual dysfunction is 4.10; $(\mathrm{AOR}=4.1,95 \% \mathrm{CI}=1.43-11.77)$; times increased among khat users when it compared with non users.

The risk of developing sexual dysfunction is increased 2.62; $\quad(\mathrm{AOR}=2.62,95 \% \mathrm{CI}=1.62-4.23) ; \quad$ and $4.76 ; \quad(\mathrm{AOR}=4.76,95 \% \mathrm{CI}=2.50-9.04)$; times among those who were not satisfied with their relationship status and among those who are not in relationship when compared with those who were satisfied with their relationship status.

However, in this study there is no significant association identified between the duration of illness, age onset of epilepsy, type of medication, medication regimen, seizure experience, comorbid medical illness, sex, marital status, BMI, life threatening events, self-steam and cigarette use (Table 4).

\section{Discussion}

In this study; the prevalence and possible factors associated with sexual dysfunction among PWE were assessed; as the result indicated the prevalence of global sexual dysfunction found higher and it is more prevalent among males than females.

This finding is higher when compared with the study conducted in Los Angeles and Egypt (50 and 59.3\% respectively) [10, 15]. The possible reason might be 
Table 3 Distribution of clinical factors by sex among patient with epilepsy at Amanuel Mental Specialized Hospital: Addis Ababa, Ethiopia; 2016

\begin{tabular}{|c|c|c|c|}
\hline Variable & Over all sample: $n=694$ & Female: $n=234$ & Male: $n=460$ \\
\hline \multicolumn{4}{|c|}{ Age onset of Epilepsy: n (\%) } \\
\hline$<5$ years & $97(14.00)$ & $33(14.10)$ & $64(13.90)$ \\
\hline $5-14$ & $167(24.10)$ & $62(26.50)$ & $105(22.80)$ \\
\hline $15-24$ & $253(36.50)$ & $74(31.60)$ & $179(38.90)$ \\
\hline $25-34$ & 99 (14.30) & $42(17.90)$ & $57(12.40)$ \\
\hline $35-44$ & $62(8.90)$ & $20(8.50)$ & $42(9.10)$ \\
\hline$>44$ & $16(2.30)$ & $3(1.30)$ & $13(9.10)$ \\
\hline \multicolumn{4}{|l|}{ Seizure experience } \\
\hline \multicolumn{4}{|l|}{ Not controlled } \\
\hline Severe & $270(38.90)$ & $101(43.20)$ & $169(36.70)$ \\
\hline Moderate & $72(10.40)$ & $27(11.50)$ & $45(9.80)$ \\
\hline Mild & $169(24.40)$ & $52(22.20)$ & $117(25.40)$ \\
\hline Controlled & $183(26.40)$ & $54(23.10)$ & $129(28.00)$ \\
\hline \multicolumn{4}{|c|}{ Medication Regimens: n (\%) } \\
\hline Mono therapy & $541(78.10)$ & $178(76.10)$ & $363(79.10)$ \\
\hline Poly therapy & $152(21.90)$ & $56(23.90)$ & $96(20.90)$ \\
\hline \multicolumn{4}{|c|}{ Types of medication: n (\%) } \\
\hline Phenobarbitone & $557(80.30)$ & $197(84.20)$ & $360(78.30)$ \\
\hline Carbamazepine & $128(18.40)$ & $34(14.50)$ & $94(20.40)$ \\
\hline Phenytoin & $94(13.50)$ & $33(41.10)$ & $61(13.30)$ \\
\hline Na-valporate & $53(7.60)$ & $20(8.50)$ & $33(7.20)$ \\
\hline \multicolumn{4}{|c|}{ Co morbid illness: n (\%) } \\
\hline Yes & $170(24.50)$ & $59(25.20)$ & $111(24.10)$ \\
\hline No & $524(75.50)$ & $175(74.80)$ & $349(75.90)$ \\
\hline \multicolumn{4}{|c|}{ Medical co-morbidities: n (\%) } \\
\hline Hypertension & $43(6.20)$ & $22(9.40)$ & $21(4.60)$ \\
\hline Diabetics & $36(5.20)$ & $21(9.00)$ & $15(3.30)$ \\
\hline HIV & $41(5.90)$ & $30(12.80)$ & $11(2.40)$ \\
\hline Other & $9(1.30)$ & $5(2.10)$ & $4(0.90)$ \\
\hline \multicolumn{4}{|c|}{ Psychiatric co-morbidities: n (\%) } \\
\hline Psychosis & $21(3.00)$ & $9(3.80)$ & $12(2.60)$ \\
\hline Depression & $34(4.90)$ & $17(7.30)$ & $17(7.30)$ \\
\hline \multicolumn{4}{|c|}{ Medication for co-morbid illness: n (\%) } \\
\hline Yes & $82(11.80)$ & $41(17.50)$ & $41(8.90)$ \\
\hline No & $611(88.00)$ & $193(82.50)$ & $419(91.00 \%)$ \\
\hline \multicolumn{4}{|l|}{ BMI: n (\%) } \\
\hline Under weight & $73(10.50)$ & $32(13.70)$ & $41(8.90)$ \\
\hline Normal weight & $515(74.20)$ & $156(66.70)$ & $359(78.00)$ \\
\hline Over weight & $106(15.30)$ & 46 (19.70) & $60(13.00)$ \\
\hline
\end{tabular}

differences in; study design (those studies use case and control), sample size (60 cases in Los Angeles and 27cases in Egypt), and variance in socioeconomic characteristics of participants.
The result of sexual dysfunction among male participants was relatively higher (67\%) when it compared with the study conduct in Egypt (61\%). The possible reasons may the Egypt one was experimental study (investigating 


\section{Global sexual dysfunction among people with epilepsy}

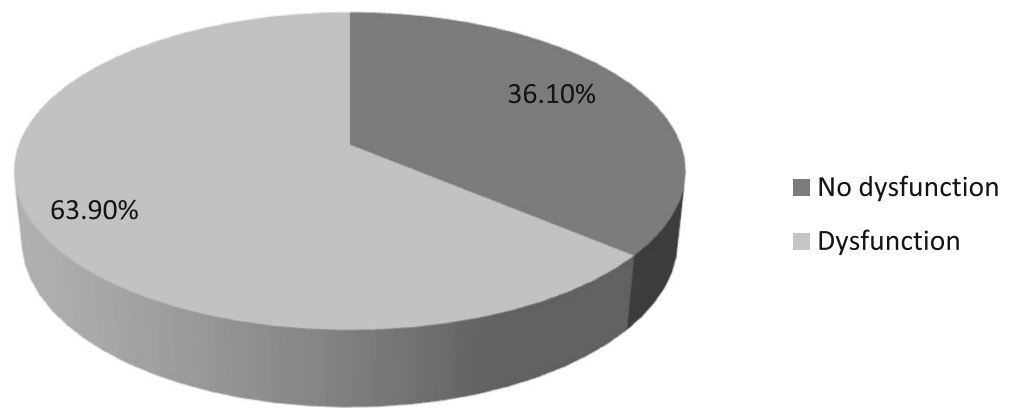

Fig. 1 Prevalence of global sexual dysfynction among people with epilepsy at Amanuel Mental Specialized hospital: Addis Ababa; Ethiopia$2016(n=576)$

Serological and psychological interviews together with serum total testosterone) [16].

Among domains of global sexual dysfunctions, arousal dysfunction has slightly higher prevalent than other domains of sexual dysfunctions; pleasure dysfunction, sexual desire problem and orgasm dysfunction. By the other side dyspareunia was less prevalent sexual dysfunction.

The result of arousal dysfunction among male participants was very high in this study when it compared with other studies conducted on patient with epilepsy. In Iran the prevalence of erectile dysfunction (ED) was $42.5 \%$ which is less compared with the results from Massachusetts $52 \%[17,18]$. In Egypt; erectile dysfunction (ED) and premature ejaculation represented 70.4 and $66.7 \%$, respectively [16]. This difference may be due to cultural difference, availabilities of clinical services and variance in attitude and practices of professionals \& participants among study populations.
The study conducted in India; Sri Shivarathreeshwara Hospital was disclosed that; prevalence of clinically significant impairment in different domains of sexual dysfunction is 2-3 times higher in women with epilepsy. This prevalence ranges from $70 \%$ (impaired desire) to 98\% (impairments in orgasmic functioning) in individual sexual domains, and is $72 \%$ for the prevalence of clinically significant impaired global sexual functioning. In this study; its prevalence is higher in desire part and lower in orgasmic dysfunction among females. In global prevalence of clinically significant impaired sexual functioning among females, its prevalence is lower in this study. These differences might happen because of sociocultural contexts of study participants in this study to disclose ones sexual experiences [19].

The study conducted in North America report recurrent pain during intercourse is in line $(15 \%)$ with prevalence of dyspareunia among FWE in this study [20].

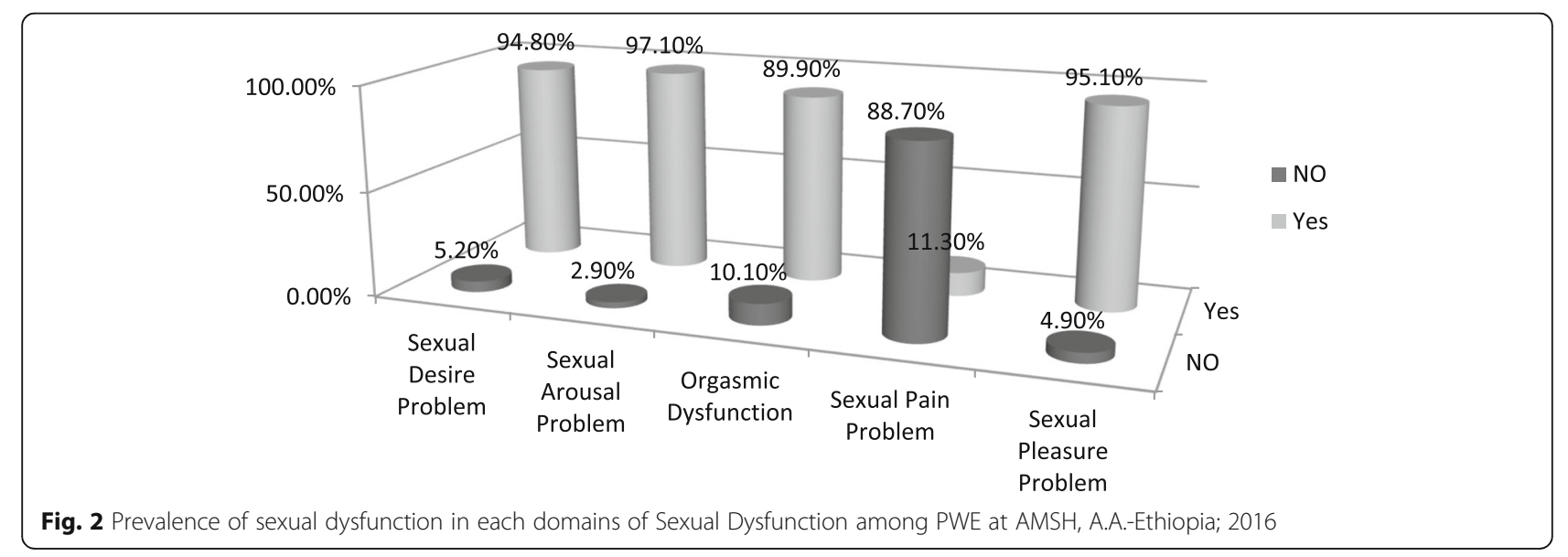




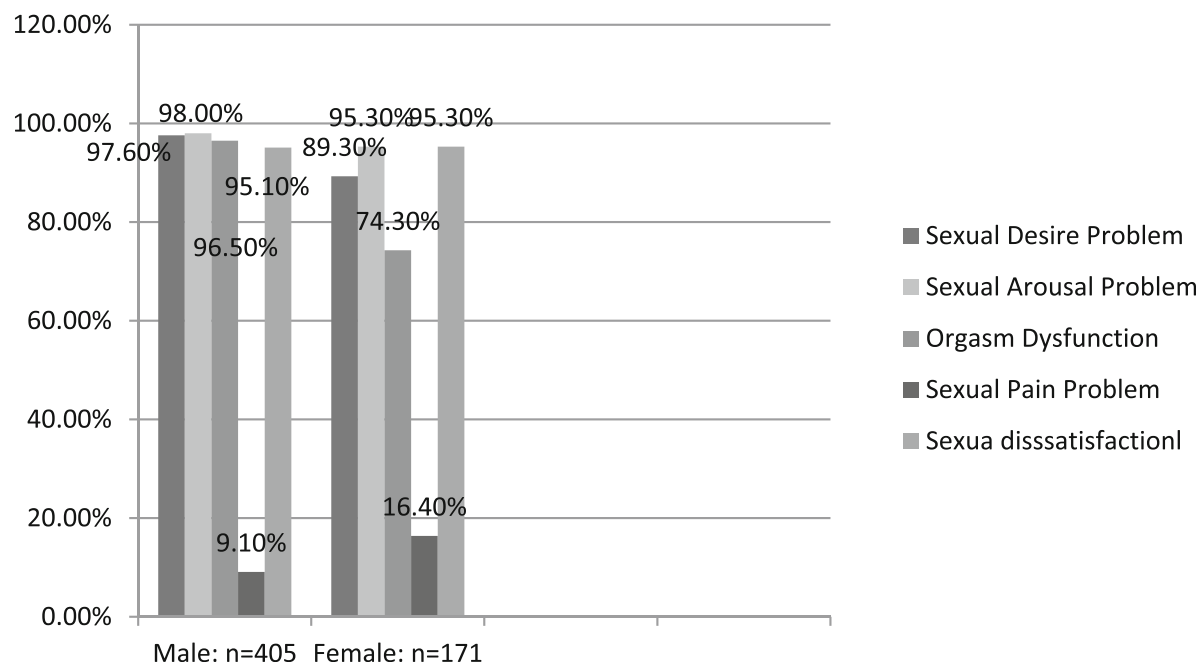

Fig. 3 Prevalence of sexual dysfunction in each domains by sex at AMSH, A.A.-Ethiopia; 2016

High prevalence of sexual pain problem is not common among MWE as well in general population. In this study unusual increased in prevalence of sexual pain problem among MWE might be probably because of assessment toll (a single question with above average cut of point; 4 and less out of 5) to screen sexual pain problem.

The odds of developing sexual dysfunction is increased 3.23 times among age groups above 51 years old than in the age groups $21-30$.

The odds of developing sexual dysfunction are 6.3 times increased among depressed patients when it compared with people without depression.

The odds of developing sexual dysfunction are 2.64 times increased among jobless when it compared with the employed one. In the variable participants educational status, the odds of developing sexual dysfunction is decreased by $66 \%$ among educational level at $2^{\text {ndry }}$ School compared with those at primary level. Also the odds of developing sexual dysfunction were decreased by $70 \%$ among diploma holders. It may because of having better awareness about communication, their disease control, sexual life and sexuality among more educated groups than groups at primary level of education.

In this study the risk of developing sexual dysfunction is increased 2.61 times among participants who were not satisfied with non-sexual aspects of their relationship than those who were satisfied. Also its odds were increased 4.76 times among who is not in relationship despite they have sexual experience. This association may occur because of instability on relationship, felling of insecurity, and having sexual practice with strangers. Also impaired sexual dysfunction probably may predispose PWE to be not in relationship. This causal association cannot be made on cross sectional data. Participants those satisfied in non-sexual aspects of relationship may relatively free from psychological factors relating intimacy/relationship and sexuality. According to synopsis of psychiatry 11th edition; the availability of an appropriate partner and a good relationship in non-sexual areas with a partner are among factors affecting once sexual functioning. Damage to, or absence of, any of these factors can diminish desire [16].

Other studies were shown that most of the psychological elements; Self-esteem, quality of relationship, stressful life events; that can interfere in a sexual response can behave in an indiscriminate manner in individuals with or without epilepsy, but in the case of PWE, it appears that the negative-subjective attribution related to "being sick" produces certain behavioral problems that interfere with the sexual response $[1,2,10,21]$.

The odds of developing sexual dysfunction among alcohol users are decreased by $74 \%$ when it compared with non users. In this study amount, frequency, concentration and alcohol use behavior of participants were not assessed in detailed and this protective effects of alcohol might occur because of a relaxant effect of it in small amounts. As synopsis of psychiatry 11th edition discussed;
Abused recreational substances affect sexual function in various ways. In small doses, many substances enhance sexual performance by decreasing inhibition or anxiety or by causing a temporary elevation of mood. Alcohol may foster the initiation of sexual activity by removing inhibition, but it also impairs performance. With continued use, however, erectile engorgement and orgasmic and ejaculatory capacities become impaired $[5,16]$. 
Table 4 Factors which has association on binary logistic regression among patient with epilepsy: Amanuel Mental Specialized Hospital, Addis Ababa, Ethiopia- 2016

\begin{tabular}{|c|c|c|c|c|}
\hline \multirow[t]{3}{*}{ Variables } & \multicolumn{4}{|c|}{ Results: $n=576$} \\
\hline & \multicolumn{2}{|c|}{ Sexual dysfunction } & \multirow[t]{2}{*}{$\operatorname{COR}(\mathrm{Cl}=95 \%)$} & \multirow[t]{2}{*}{$\mathrm{AOR}(\mathrm{Cl}=95 \%)$} \\
\hline & Yes & No & & \\
\hline \multicolumn{5}{|l|}{ Socio-demographic factors } \\
\hline \multicolumn{5}{|l|}{ Age } \\
\hline$<21$ & 20 & 20 & $0.52(0.26-1.01)^{*}$ & $0.26(.012-0.60)^{* *}$ \\
\hline $21-30$ & 159 & 82 & 1.00 & 1.00 \\
\hline $31-40$ & 112 & 56 & $1.03(0.68-1.56)$ & $1.44(0.85-2.42)$ \\
\hline $41-50$ & 34 & 40 & $0.44(0.26-0.74)^{* *}$ & $0.68(0.33-1.39)$ \\
\hline$>51$ & 43 & 10 & $2.22(1.06-4.64)^{*}$ & $3.23(1.21-8.66)^{*}$ \\
\hline \multicolumn{5}{|l|}{ Marital status } \\
\hline Married & 171 & 77 & 1.00 & 1.00 \\
\hline Single & 177 & 121 & $0.66(0.46-0.94)^{*}$ & $0.66(0.40-1.08)$ \\
\hline Divorced & 7 & 5 & $0.63(0.19-2.05)$ & $0.29(0.62-1.34)$ \\
\hline Other & 13 & 5 & $1.17(0.40-3.40)$ & $0.45(0.12-1.65)$ \\
\hline \multicolumn{5}{|l|}{ Educational Status } \\
\hline Primary & 65 & 24 & 1.00 & 1.00 \\
\hline No formal education & 118 & 60 & $0.73(0.41-1.30)$ & $0.52(0.26-1.03)$ \\
\hline Secondary & 136 & 84 & $0.60(0.35-1.02)^{*}$ & $0.35(0.17-0.71)^{* *}$ \\
\hline Diploma & 31 & 27 & $0.42(0.21-0.85)^{* *}$ & $0.29(0.12-0.72)^{* *}$ \\
\hline$>=$ Degree & 17 & 13 & $0.48(0.20-1.19)^{*}$ & $0.42(0.15-1.19)$ \\
\hline \multicolumn{5}{|l|}{ Occupation } \\
\hline Employee & 108 & 83 & 1.00 & 1.00 \\
\hline Jobless & 80 & 24 & $2.65(1.50-4.39)^{* *}$ & $2.64(1.36-5.12) * *$ \\
\hline Self employee & 123 & 50 & $1.89(1.22-2.92)^{*}$ & $1.70(1.02-2.83)^{*}$ \\
\hline House wife & 20 & 19 & $0.81(0.41-1.61)$ & $0.96(0.42-6.02)$ \\
\hline Student & 11 & 7 & $1.21(0.45-3.25)$ & $1.64(0.45-6.03)$ \\
\hline Farmer & 26 & 25 & $0.80(0.43-1.48)$ & $0.70(0.32-1.52)$ \\
\hline \multicolumn{5}{|l|}{ Clinical factors } \\
\hline \multicolumn{5}{|l|}{ Depression } \\
\hline Yes & 23 & 5 & $2.71(1.01-7.23)^{*}$ & $6.28(1.67-23.61)^{* *}$ \\
\hline No & 345 & 203 & 1.00 & 1.00 \\
\hline \multicolumn{5}{|l|}{ Anti Epileptic Drugs } \\
\hline \multicolumn{5}{|l|}{ Phenobarbitone } \\
\hline Yes & 294 & 167 & $0.91(0.64-1.50)$ & - \\
\hline No & 74 & 41 & 1.00 & - \\
\hline \multicolumn{5}{|l|}{ Carbamazepine } \\
\hline Yes & 70 & 32 & $0.27(0.82-2.04)$ & $0.31(0.80-2.01)$ \\
\hline No & 298 & 176 & 1.00 & 1.0 \\
\hline \multicolumn{5}{|l|}{ Phenytoin } \\
\hline Yes & 41 & 33 & $0.11(0.41-1.09)^{*}$ & $0.12(0.41-1.11)$ \\
\hline No & 327 & 175 & 1.00 & 1.00 \\
\hline \multicolumn{5}{|l|}{$\mathrm{Na}$ - valporate } \\
\hline Yes & 24 & 18 & $0.35(0.39-1.39)$ & - \\
\hline
\end{tabular}


Table 4 Factors which has association on binary logistic regression among patient with epilepsy: Amanuel Mental Specialized Hospital, Addis Ababa, Ethiopia- 2016 (Continued)

\begin{tabular}{|c|c|c|c|c|}
\hline \multirow[t]{3}{*}{ Variables } & \multicolumn{4}{|c|}{ Results: $n=576$} \\
\hline & \multicolumn{2}{|c|}{ Sexual dysfunction } & \multirow[t]{2}{*}{$\operatorname{COR}(\mathrm{Cl}=95 \%)$} & \multirow[t]{2}{*}{$\mathrm{AOR}(\mathrm{Cl}=95 \%)$} \\
\hline & Yes & No & & \\
\hline No & 18 & 190 & 1.00 & - \\
\hline \multicolumn{5}{|c|}{ Current Substance use behaviors } \\
\hline \multicolumn{5}{|l|}{ Khat } \\
\hline Yes & 26 & 7 & $2.18(0.93-5.12)^{*}$ & $4.10(1.43-11.77)^{* *}$ \\
\hline No & 342 & & 1.00 & 1.00 \\
\hline \multicolumn{5}{|l|}{ Alcohol } \\
\hline Yes & 9 & 10 & $0.5(0.2-1.24)^{*}$ & $0.26(0.08-0.87)^{*}$ \\
\hline No & 359 & & 1.00 & 1.00 \\
\hline \multicolumn{5}{|l|}{ Stressful life events } \\
\hline Yes & 293 & 183 & $0.53(0.33-0.87)^{*}$ & $0.59(0.32-1.04)$ \\
\hline No & 75 & 25 & 1.00 & 1.00 \\
\hline \multicolumn{5}{|c|}{ Relationship status (couple's satisfaction) } \\
\hline Satisfied & 146 & 137 & 1.00 & 1.00 \\
\hline Not satisfied & 130 & 49 & $2.49(1.66-3.73)^{* * *}$ & $2.62(1.632-4.23)^{* * *}$ \\
\hline Not in relationship & 92 & 22 & $3.92(2.33-6.60)^{* * *}$ & $4.76(2.56-9.04)^{* * *}$ \\
\hline
\end{tabular}

N.B. ${ }^{*}=p$-value $<0.05,{ }^{* *} p$-value $<0.01,{ }^{* * *} p$-value $<0.001$

COR Crude Odds Ratio, AOR Adjusted Odds Ratio

In this case detailed study is important in alcohol use behaviors of study participants to clarify its effect. Most studies find that, PWE are prone to anxiety and inhibition due to their illnes than people without epilepsy $[2$, $5,10]$. That problem may lead them to use small amount of alcohol to alleviate their anxiety and inhibition at the time of sexual intercourse. This may be another reason behind this negative association between sexual dysfunction and alcohol use.

The risk of developing sexual dysfunction is 4.1 times increased among khat users when it compared with non users. Meta analysis conducted on published data and limited interviews of regular khat users at East African's revealed that khat chewing lowers libido in humans and may also lead to sexual impotence following long term use [16].

Type of AEDs (Phenobarbitone, Phenytoin, Carbamazepine, and valporate), medication regimen (polytherapy), age onset of epilepsy, and frequency of seizure experience, body mass, self-esteem, and other variables do not appear to have an independent effect on global sexual functioning.

\section{Conclusion}

The prevalence of global sexual dysfunction among patient with epilepsy found to be higher at Amanuel Mental Specialized Hospital PWE Outpatient clinics. Its prevalence is more on male with epilepsy than females.
Among domains of sexual dysfunctions arousal and sexual pain problems were the most \& the least prevalent types of sexual dysfunctions respectively. This shows that; it is significant clinical health problem that require a great emphasis.

Although further research will be needed to elucidate the underlying mechanisms of association, this study weighted the data from AMSH, 2016 to succeed in identifying a statistically significant association between sexual dysfunction and the following variables; age, joblessness, level of education, depression, relationship satisfaction, khat use and alcohol use. AEDs and medication regimen (polytherapy) was among variables found as statistically significant in the binary logistic (crude analysis) but it was not statistically significant in multivariable logistic regression.

\section{Additional files}

Additional file 1: Dataset for each domains of sexual dysfunction. (CSV 154 kb)

Additional file 2: Dataset for global sexual dysfunction among patient with epilepsy. (CSV $125 \mathrm{~kb}$ )

Additional file 3: Dataset for sexual dysfunction among female participants. (CSV 54 kb)

Additional file 4: Dataset for sexual dysfunction among male participants. (CSV $106 \mathrm{~kb}$ ) 


\section{Abbreviations}

AA: Addis Ababa; AEDs: Anti Epileptic Drugs; AMSH: Amanuel Mental Specialized Hospital; BMI: Body Mass Index; CSI: Couple Satisfaction Index; DSLEM: Daily Stressful Life Events Measurement; ED: Erectile Dysfunction; Epi.Info: Epidemiological Information; FEW: Female with Epilepsy; HIV/ AIDS: Human Immune compromising viruses/ Acquired Immune Deficiency Disorders; Kg: Kilo gram; $\mathrm{m}^{2}$ : Meter square; MWE: Male with Epilepsy; NEP: Neuropsychiatric; NHSLS: National Health and Social Survey; OPD: Out Patient Department; PE: Premature Ejaculation; PWE: Patient with Epilepsy; PWE: Peoples with Epilepsy; RAS: Relationship Assessment Scale; SD: Sexual dysfunction; SES: Self-esteem Scale SLE: Stressful life events; SPSS: Statistical Package for Social Science; TLE: Temporal Lobe Epilepsy; UOG: University of Gondar

\section{Acknowledgments}

The Authors would like to acknowledge Amanuel Mental Specialized Hospital Research and Training Center; and University of Gondar Psychiatry Department staffs for their timely professional supports to complete this study. The Author would also like to thank Amanuel Mental Specialty Hospital NEP department Staffs who were facilitating data collection procedure, all study participants, all data collectors and supervisors.

\section{Authors' contributions}

AKE: Principal Investigator, Corresponding author; Participated in the conception and design of the study, wrote the proposal, participate in data analysis and write up of this manuscript. NYM: Consulted on proposal development, report writing, presentation, manuscript writing and approval of final manuscript. KHZ: Consultation on proposal development, report writing \& presentation. ZRS, MWG and YHB: Participated on training of data collectors, supervision, data management, entry and analysis. All authors read and approved the final manuscript.

\section{Authors' information}

AKE. is principal investigator, Corresponding author; BSc in Public health Profession, MA in Adult education \& lifelong learning -AAU and MSC in integrated clinical and community mental Health - UOG. She is working at Amanuel Mental specialty hospital since 2009.

$\mathrm{KHZ}$. - BSC in Professional Nurse and MSc in integrated clinical and community mental Health-UOG. Currently working at Amanuel Mental Specialty Hospital central statistic Bureau.

NYM. - BSC, MSc, Assistant professor of Mental Health; College of Medicine \& Health science; Institutional review Board officer - University of Gondar: Gondar, Ethiopia.

ZRS. - BSC in Public health Profession, MSc in Integrated Clinical and Community Mental Health-UOG. Since 2009; working at Amanuel Mental specialty hospital.

MWG. - BSc in Public health Profession, MSc in Integrated Clinical and Community Mental Health- UOG. Since 2009; working at Amanuel Mental specialty hospital.

YHB. - BSc in Public health Profession, MSc in Integrated Clinical and Community Mental Health- UOG. Since 2009; working at Amanuel Mental specialty hospital.

Institute of Public Health, College of Medicine and Health Sciences, University of Gondar, Gondar, Ethiopia.

\section{Funding}

Amanuel Mental Specialized Hospital Research and Training Center covered secretarial expenditure and data collectors' fee. Principal investigator covered nalysis and interpretation of data; and in writing the manuscript.

\section{Availability of data and materials}

The datasets generated and analyzed during this study are available as Additional files 1, 2, 3, 4 .

\section{Ethics approval and consent to participate}

Ethical clearance was obtained from institution review board (IRB) of University of Gondar with Ref. No. $\mathbf{a q / 1 4 6 / 1 / 7 9 4}$. Then an official permission and letter of collaboration was obtained from University of Gondar and Amanuel Mental Specialty Hospital (AMSH) then after the letter submitted to AMSH Neuro-Epileptic unit.
The purpose, importance and confidentiality of the study were well explained to each participant before they engage in to actual activities. Confidentiality was maintained at all levels of the study by avoiding use of name and other identifiers. Participants were informed that they will never get any benefit because of part of the study and no harm on them if they were not agree to participate or withdraw participation on the study. Finally, they were asking about their willingness to participate on the study and written consent was obtained.

At the time of data collection principal investigator, supervisors and data collectors were expected to follow 'code of ethics' and to obey for the rules \& regulations of NEP department. Participant's privacy was kept strictly at the time of data collection. Two separate OPDs were used for each sex categories.

Participants; 17(2.45\%); with complains of sexual issues were linked to related professionals for detailed history on sexual issues and for possible management.

\section{Consent for publication}

Not applicable.

\section{Competing interests}

The authors declare that they have no competing interests.

\section{Author details}

${ }^{1}$ Addis Ababa, Ethiopia. ${ }^{2}$ UOG, Gondar, Ethiopia.

Received: 10 January 2018 Accepted: 18 August 2019

Published online: 27 October 2019

\section{References}

1. Pritchard P. Hypo-sexuality-a complication of complex partial epilepsy. In: Annals of neurology: 1980. Philadelphia: Lippincott-Raven Publ; 1980. p. 104

2. Luef GJ. Epilepsy and sexuality. Seizure. 2008;17(2):127-30.

3. Calabrò RS, Grisolaghi J, Quattrini F, Bramanti P, Magaudda A. Prevalence and clinical features of sexual dysfunction in male with epilepsy: the first southern Italy hospital-based study. Int J Neurosci. 2013;123(10):732-7.

4. Association AP: Diagnostic and statistical manual of mental disorders (DSM-5 ${ }^{\oplus}$ ): American Psychiatric Pub; 2013.

5. Sadock BJ, Sadock VA. Kaplan and Sadock's synopsis of psychiatry: behavioral sciences/clinical psychiatry. New York: Lippincott Williams \& Wilkins; 2011.

6. Smaldone M, Sukkarieh T, Reda A, Khan A. Epilepsy and erectile dysfunction: a review. Seizure. 2004;13(7):453-9.

7. Rosen RC. Prevalence and risk factors of sexual dysfunction in men and women. Current Psychiatry Reports. 2000;2(3):189-95.

8. Aron A, Norman CC, Aron EN, McKenna C, Heyman RE. Couples' shared participation in novel and arousing activities and experienced relationship quality. J Pers Soc Psychol. 2000;78(2):273.

9. Gable SL, Reis HT, Impett EA, Asher ER. What do you do when things go right? The intrapersonal and interpersonal benefits of sharing positive events. J Pers Soc Psychol. 2004;87(2):228.

10. Souza EAP, Keiralla D, Silveira DC, Guerreiro CA. Sexual dysfunction in epilepsy: identifying the psychological variables. Arq Neuropsiquiatr. 2000: 58(2A):214-20.

11. burau CS: Top ten disease report in. Edited by bureau Cs; 2007 .

12. Clayton $\mathrm{AH}$. Reliability and construct validity of the changes in sexual functioning questionnaire short-form (CSFQ-14). J Sex Marital Therapy. 2006; 32:43-52.

13. Funk $\lrcorner$, Rogge RD. Testing the ruler with item response theory: increasing precision of measurement for relationship satisfaction with the couples satisfaction index. J Fam Psychol. 2007;21(4):572.

14. Alemu KS. Contribution of khat kellas and the impacts of its closure to Ethiopian economy (the case of Hararghe khat kella). Global Journal of Management And Business Research. 2015.

15. Elnashar A, EL-Dien Ibrahim M, El-Desoky M, Ali O, El-Sayd Mohamed Hassan M. Female sexual dysfunction in Lower Egypt. BJOG Int J Obstet Gynaecol. 2007:114(2):201-6.

16. Hamed S, Mohamed K, El-Taher A, Hamed E, Omar H. The sexual and reproductive health in men with generalized epilepsy: a multidisciplinary evaluation. Int J Impot Res. 2006;18(3):287-95. 
17. Hellmis E. Sexual problems in males with epilepsy—an interdisciplinary challenge! Seizure. 2008;17(2):136-40.

18. Mölleken D, Richter-Appelt H, Stodieck S, Bengner T. Sexual quality of life in epilepsy: correlations with sex hormone blood levels. Epilepsy Behav. 2009; 14(1):226-31.

19. Karan V, Harsha S, Keshava B, Pradeep R, Rao TS, Andrade C. Sexual dysfunction in women with epilepsy. Indian J Psychiatry. 2015;57(3):301.

20. Goshtasebi A, Foroushani AR, Gandevani SB. Prevalence of sexual dysfunctions: a systemic approach: INTECH Open Access Publisher; 2011.

21. Calabrò RS, Marino S, Bramanti P. Sexual and reproductive dysfunction associated with antiepileptic drug use in men with epilepsy. Expert Rev Neurother. 2011;11(6):887-95.

\section{Publisher's Note}

Springer Nature remains neutral with regard to jurisdictional claims in published maps and institutional affiliations.

- fast, convenient online submission

- thorough peer review by experienced researchers in your field

- rapid publication on acceptance

- support for research data, including large and complex data types

- gold Open Access which fosters wider collaboration and increased citations

- maximum visibility for your research: over $100 \mathrm{M}$ website views per year

At $\mathrm{BMC}$, research is always in progress. 